\title{
Dynamics of bacterial community succession in a salt marsh chronosequence: evidences for temporal niche partitioning
}

\author{
Francisco Dini-Andreote ${ }^{1}$, Michele de Cássia Pereira e Silva ${ }^{1}$, Xavier Triadó-Margarit ${ }^{2}$, \\ Emilio O Casamayor ${ }^{2}$, Jan Dirk van Elsas ${ }^{1}$ and Joana Falcão Salles ${ }^{1}$ \\ ${ }^{1}$ Department of Microbial Ecology, Centre for Ecological and Evolutionary Studies, University of Groningen, \\ Groningen, The Netherlands and ${ }^{2}$ Biogeodynamics and Biodiversity Interactions Group, Centre d'Estudis \\ Avançats de Blanes, CEAB-CSIC, Blanes, Catalunya, Spain
}

\begin{abstract}
The mechanisms underlying community assembly and promoting temporal succession are often overlooked in microbial ecology. Here, we studied an undisturbed salt marsh chronosequence, spanning over a century of ecosystem development, to understand bacterial succession in soil. We used 16S rRNA gene-based quantitative PCR to determine bacterial abundance and multitag 454 pyrosequencing for community composition and diversity analyses. Despite 10-fold lower 16S rRNA gene abundances, the initial stages of soil development held higher phylogenetic diversities than the soil at late succession. Temporal variations in phylogenetic $\beta$-diversity were greater at initial stages of soil development, possibly as a result of the great dynamism imposed by the daily influence of the tide, promoting high immigration rates. Allogenic succession of bacterial communities was mostly driven by shifts in the soil physical structure, as well as variations in $\mathrm{pH}$ and salinity, which collectively explained $84.5 \%$ of the variation concerning community assemblage. The community assembly data for each successional stage were integrated into a network co-occurrence analysis, revealing higher complexity at initial stages, coinciding with great dynamism in turnover and environmental variability. Contrary to a spatial niche-based perspective of bacterial community assembly, we suggest temporal niche partitioning as the dominant mechanism of assembly (promoting more phylotype co-occurrence) in the initial stages of succession, where continuous environmental change results in the existence of multiple niches over short periods of time.
\end{abstract}

The ISME Journal (2014) 8, 1989-2001; doi:10.1038/ismej.2014.54; published online 17 April 2014

Subject Category: Microbial population and community ecology

Keywords: bacterial succession; environmental chronosequence; temporal niche; phylotypes co-occurrence; network analysis

\section{Introduction}

Understanding the factors that modulate the spatiotemporal changes in the composition of communities along environmental gradients is a central theme in ecology (Tilman, 1988; Grime, 2001; Van der Maarel, 2004). Macro-ecologists have a long history of research on temporal dynamics of community composition in animals and plants (Preston, 1960; Johnson, 1979; Ives et al., 2003), resulting in an integrated set of concepts that are used for the modelling of such communities. In particular, studies on the long-term changes in

Correspondence: F Dini-Andreote, Department of Microbial Ecology, Centre for Ecological and Evolutionary Studies, University of Groningen, Nijenborgh 7, 9747 AG Groningen, The Netherlands.

E-mail: f.dini.andreote@rug.nl

Received 4 October 2013; revised 24 February 2014; accepted March 2014; published online 17 April 2014 macro-organismal diversity have been instrumental in helping ecologists to establish a framework to understand and model successional dynamics (Lockwood et al., 1997; Chase, 2003). For such studies, the use of chronosequences, which assume a space-for-time substitution, despite a few criticisms (for a review see Johnson and Miyanishi, 2008), has offered unique opportunities to investigate soil macro-community development across multiple time scales, in some cases spanning over hundreds of years of (ordered) temporal changes (Bormann and Sidle, 1990; Breen and Lévesque, 2006; reviewed in detail by Walker et al., 2010).

The few studies that so far have assessed the successional patterns of microbial communities along environmental chronosequences have focused on receding glacier forelands (Sigler and Zeyer, 2002; Nicol et al., 2005; Deiglmayr et al., 2006; Nemergut et al., 2007; Schmidt et al., 2008; Schütte et al., 2009; Wu et al., 2012), abandoned agricultural 
fields (Elhottová et al., 2002; Kuramae et al., 2010) and post-mining areas (Hüttl and Weber, 2001; Kozdrój and van Elsas, 2001). As an extension from what we know on successional dynamics of communities of larger organisms, we would expect microbial succession trajectories to present a continuing time series determined by orderly changes in environmental parameters, towards an increase of biological diversity and complexity (as observed for plant succession, Walker and del Moral, 2003). However, the aforementioned studies focusing on microbial communities have shown contradictory results. For instance, it is unclear whether or not microbes obey the conceptual framework observed for plants. Although a few studies have reported an increase of species richness and diversity towards succession (Nemergut et al., 2007), others have described the opposite pattern (Sigler and Zeyer, 2002; Hodkinson et al., 2003). Moreover, it is uncertain whether microbial 'climax' communities (sensu Clements (1916)) actually exist, rendering any end point of succession somewhat arbitrary (Fierer et al., 2010). Defining an appropriate time frame for examining succession is exceedingly difficult, as different parameters may act at different time scales and incidental disturbances can strongly alter any pattern of successional change (Chapin et al., 1994; Turner et al., 1998). Studies that examined temporal variability in soil microbial communities have indicated that the local microbiota can vary at the daily (Zhang et al., 2011), seasonal (Schadt et al., 2003; Lipson, 2007) and/or yearly scale (Salles et al., 2006; DeBruyn et al., 2011). Therefore, different time frames must be tested and adjusted to local environmental conditions in order to properly assess and predict bacterial assemblages and community trajectories along successional chronosequences.

The eastern North Sea front of the barrier island of Schiermonnikoog, The Netherlands, constitutes a well-documented and undisturbed salt marsh ecosystem, which spans over 100 years of succession (Olff et al., 1997). This ecosystem has served as a model to investigate the dynamics of the local food webs and ecosystem functioning and maintenance for more than a decade. In these studies, the effect of the interplay between below- and aboveground communities (providing different types of ecological and biogeochemical processes) on ecosystem buildup and development was raised as a key issue (Olff et al., 1997; Schrama et al., 2012). The assembly of communities of higher organisms over time was described as an intricate interplay of green and brown food webs, resulting in an initially marine (brown; microbially/chemically based) driven system to a mainly terrestrial (green; plant based) one later (Schrama et al., 2012). Also, the occurrence of microbial mats at primary sites was shown to have an important role in coastal protection and morphodynamics through sediment stabilization and the initiation of salt marsh development (Bolhuis and Stal, 2011).

In the current study, we aim at understanding what drives the dynamics of soil bacterial communities along the salt marsh chronosequence. We hypothesized that such drivers are different across the stages of the chronosequence. Specifically, we focused on three main ecological aspects:

(i) the relationship between abiotic factors and bacterial community assemblages (defined from now on as abiotically driven or, in macroecology terms, allogenic succession),

(ii) temporal variations in bacterial phylogenetic $\beta$-diversity and

(iii) co-occurrence of bacterial types, as assessed by network analysis of the communities from each stage of the chronosequence.

As a specific hypothesis, we expected abiotics (allogenic succession) to have the main role in shaping the bacterial communities along the chronosequence. Greater variation in environmental conditions might have added a temporal component to this driving force at initial succession as a result of the influence of the tide. Moreover, we expected the level of phylotype co-occurrence to gradually increase over successional time, as imposed by spatially explicit niche distribution, as the multiplicity of nutrients and local conditions is expected to be raised in the soils at late succession owing to the higher soil organic matter (OM) levels, as well as the elevated plant diversity and productivity.

\section{Materials and methods}

\section{Study site and sample collection}

The island of Schiermonnikoog is located at $\mathrm{N} 53^{\circ} 30^{\prime}$ E6 ${ }^{\circ} 10^{\prime}$ and presents a well-documented salt marsh chronosequence, which spans more than 100 years of succession (Olff et al., 1997). Salt marsh age at each stage of succession was estimated from topographic maps, aerial photographs and the thickness of the sediment layer accumulating on top of the underlying sand layer (Olff et al., 1997; Schrama et al., 2012). In addition, permanent plots have monitored the space-for-time replacement of this succession in different successional stages for more than 20 years (Van Wijnen et al., 1997). For this study, five successional stages were identified, estimated as 0, 5, 35, 65 and 105 years of soil development (referred from now on as 'years') in 2012 (Supplementary Figure S1). In each successional stage, triplicate $5 \times 5 \mathrm{~m}^{2}$ plots, separated from each other by $25 \mathrm{~m}$, were established at the same base of elevation (position at the initial elevation gradient on the bare sand flats with a base elevation of $1.16 \mathrm{~m} \pm 2.2 \mathrm{~cm}$ (mean \pm s.e.) above Dutch ordinance level). Differences in base elevations will have different inundation regimes, and will 
therefore differentially influence the fate of succession (Olff et al., 1997). As succession expands, the vegetation traps sediments carried by continuous cycles of inundation/recession and increases the elevation of the soil surface with $\sim 16 \mathrm{~cm}$ of clay in addition to the base elevation over 100 years (Schrama et al., 2012).

Sampling was performed in all sites at four time points: May, July, September and November 2012 (Supplementary Figure S1). For each triplicate plot, 20 soil cores $(5 \mathrm{~cm}$ diameter $\times 10 \mathrm{~cm}$ depth) were taken using sterile techniques to represent a composite sample. Each sample was placed in a sterile plastic bag, which was sealed and transported to the laboratory $(<24 \mathrm{~h})$. All samples were sieved $(4 \mathrm{~mm}$ mesh size) and stored at $-20{ }^{\circ} \mathrm{C}$ for DNA extraction and at $4{ }^{\circ} \mathrm{C}$ for physicochemical measurements. For chemical measurements, soil samples were air-dried and sieved through a 100-mesh sieve for determination of total $\mathrm{OM}$, nitrate $\left(\mathrm{N}-\mathrm{NO}_{3}^{-}\right)$, ammonium $\left(\mathrm{N}-\mathrm{NH}_{4}^{+}\right)$, sulphate $\left(\mathrm{S}-\mathrm{SO}_{4}\right)$, sodium $(\mathrm{Na})$ and $\mathrm{pH}$ (Supplementary Table S1). Physical (clay:silt:sand $\%$ content) and chemical analyses were carried out in collaboration with the Laboratory of Soil Analysis at 'Luiz de Queiroz' College of Agriculture (Department of Soil Sciences, ESALQ/USP, Piracicaba, Brazil) according to the methodology described by Van Raij et al. (2001). For soil N-NH${ }_{4}^{+}$and $\mathrm{N}_{-} \mathrm{NO}_{3}^{-}$ concentrations, the values were determined after extraction of $10 \mathrm{~g}$ of soil in $50 \mathrm{ml}$ of $2 \mathrm{M} \mathrm{KCl}$, according to the methodology described by Keeney and Nelson (1982).

Total DNA extraction and quantification of the bacterial 16S rRNA gene

A total of 60 composite soil samples (five successional stages $\times$ four temporal sampling $\times$ triplicate) were subjected to total DNA extraction using $0.5 \mathrm{~g}$ of initial material using a MoBio PowerSoil DNA extraction kit (MoBio Laboratories, Carlsbad, CA, USA) following the manufacturer's instructions, except for the addition of glass beads (diameter $0.1 \mathrm{~mm} ; 0.25 \mathrm{~g}$ ) to the soil slurries and three cycles of bead beating (mini-bead beater, BioSpec Products, Bartlesville, OK, USA) for $60 \mathrm{~s}$. Extracted DNA was further quantified using the PicoGreen doublestranded DNA assay (Invitrogen, Carlsbad, CA, USA). Quantitative PCR was used to estimate the number of 16S rRNA gene copies per gram of dryweight soil in each sample. Quantifications were carried out twice for each soil replicate in $25 \mu \mathrm{l}$ reactions containing $12.5 \mu$ l Power SYBR Green PCR Master Mix (Applied Biosystems, Frankfurt, Germany), $0.5 \mu \mathrm{l} 20 \mathrm{mg} \mathrm{ml}^{-1}$ bovine serum albumin (Roche Diagnostics $\mathrm{GmbH}$, Mannheim, Germany), $2 \mu \mathrm{l}$ of each $10 \mu \mathrm{M}$ primer (FP16S $5^{\prime}$-GGT AGT CYA YGC MST AAA CG-3' and RP16S 5'-GAC ARC CAT GCA SCA CCT G-3') targeting regions V5-V6 of the bacterial 16S rRNA gene (Bach et al., 2002) and $10 \mathrm{ng}$ sample DNA, obtaining fragments of $263 \mathrm{bp}$.
The thermal cycler protocol was $95^{\circ} \mathrm{C}$ for $10 \mathrm{~min}, 40$ cycles of $95^{\circ} \mathrm{C}$ for $27 \mathrm{~s}, 62^{\circ} \mathrm{C}$ for $1 \mathrm{~min}, 72^{\circ} \mathrm{C}$ for $30 \mathrm{~s}$, on the ABI Prism 7300 Cycler (Applied Biosystems). The specificity of the amplification products was confirmed by melting curve analysis, and the expected size of the amplified fragment was checked in a $1.5 \%$ agarose gel. A standard curve was generated over six orders of magnitude from $10^{3}$ to $10^{8}$ copies of template per essay $\left(r^{2}=0.99\right)$ using a plasmid containing cloned 16S rRNA gene from Serratia plymuthica. The quantitative PCR efficiency $(E)$ was calculated according to the equation $E=\left[10^{(-1 / \text { slope })}-1\right]$. Possible inhibitory effects of coextracted humid compounds were checked by spiking samples with a range of known concentrations of the plasmid. No apparent inhibition was observed. Data are shown as log copy numbers per gram of dry-weight soil.

Multitag pyrosequencing of partial 16S rRNA gene Twenty-five $\mu \mathrm{l}$ PCR reactions were performed in duplicate and pooled to minimize PCR bias using $0.25 \mu \mathrm{l} 5 \mathrm{U}^{-1} \mathrm{l}^{-1}$ FastStart High Fidelity Taq DNA Polymerase, $2.5 \mu \mathrm{l} 10 \times$ FastStart High Fidelity reaction buffer without $\mathrm{MgCl}_{2}, 2.3 \mu \mathrm{l} 25 \mathrm{~mm} \mathrm{MgCl}_{2}$ stock solution, $0.5 \mu \mathrm{l} 10 \mathrm{~mm}$ PCR nucleotide mix, $0.25 \mu \mathrm{l} 20 \mathrm{mg} \mathrm{ml}^{-1}$ bovine serum albumin (Roche Diagnostics $\mathrm{GmbH}$ ), $0.5 \mu \mathrm{l}$ of each $10 \mu \mathrm{m}$ primer and 10 ng sample DNA. The thermal cycling protocol was $95^{\circ} \mathrm{C}$ for $5 \mathrm{~min}, 30$ cycles of $95^{\circ} \mathrm{C}$ for $40 \mathrm{~s}, 56^{\circ} \mathrm{C}$ for $45 \mathrm{~s}, 72^{\circ} \mathrm{C}$ for $40 \mathrm{~s}$ and a final $10-m i n$ extension at $72{ }^{\circ} \mathrm{C}$. We used the primer set $515 \mathrm{f} / 1061 \mathrm{r}$ that targets regions V4-V6 of the 16S rRNA bacterial gene, which yields accurate phylogenetic information (Liu et al., 2007) and should have few biases against any bacterial taxa (Bates et al., 2011). All amplicons were run in an agarose gel $1 \%(\mathrm{w} / \mathrm{v})$ and bands containing exact sizes were excised from the gel and purified using the QIAquick Gel Extraction kit (QIAGEN $\mathrm{GmbH}$, Hilden, Germany). Purified amplicons from each duplicate reaction were pooled together, and further quantified using the PicoGreen dsDNA assay (Invitrogen). Amplicons from all samples were pooled in equimolar concentrations into two composite samples containing 30 samples each, and were sequenced at Beckman Coulter Genomics (Danvers, MA, USA) on a Roche GS-FLX 454 automated pyrosequencer running the titanium chemistry.

\section{Sequence processing and co-occurrence analysis}

Pyrosequencing raw data were demultiplexed and processed using the Quantitative Insights Into Microbial Ecology toolkit (Caporaso et al., 2010b). In brief, $16 \mathrm{~S}$ rRNA bacterial partial sequences were quality trimmed using the following parameters: quality score $>25$, sequence length $>300$ and $<900$, maximum length of homopolymer of 6,0 maximum ambiguous bases and 0 mismatched bases in the primer. Data were denoised using Denoiser (Reeder and Knight, 2010). The quality reads were then binned into operational taxonomic units 
(OTUs) at 97\% sequence identity using UCLUST (Edgar, 2010) followed by selection of a representative sequence. Chimeric sequences were identified using ChimeraSlayer (Haas et al., 2011) and removed. A representative sequence for each phylotype was aligned against the Greengenes coreset (DeSantis et al., 2006) using PyNAST (Caporaso et al., 2010a), with sequences classified using the Greengenes taxonomy via RDP classifier (Wang et al., 2007). The alignment was filtered to remove common gaps and a phylogenetic tree was constructed de novo using FastTree (Price et al., 2009). For all OTU-based analyses, the original OTU table was rarified to a depth of 2600 sequences per sample (the fewest in a single sample) to minimize effects of sampling effort on the analysis. The Quantitative Insights Into Microbial Ecology toolkit was also used to generate weighted/unweighted UniFrac distance matrices (Lozupone et al., 2006) and $\alpha$-diversity metrics, including OTU richness (unique OTUs), ChaoI richness estimation, Shannon's and Faith's phylogenetic diversity indices. All sequencing data have been deposited in the MG-RAST database (http://www.metagenomics.anl.gov/).

Non-random co-occurrence analyses were performed using SparCC, a tool capable of estimating correlation values from compositional data (Friedman and Alm, 2012). In brief, quality reads were clustered at $97 \%$ sequence identity (UCLUST, Edgar, 2010) and the 500 most abundant OTUs per stage of succession were retained for analysis. For each network analysis, $P$-values were obtained by 99 permutations of random selections of the data table, subjected to the same analytical pipeline. SparCC correlations with a magnitude $>0.6$ or $<-0.6$ and statistically significant $(P<0.01)$ were incorporated into network analyses. The nodes in the reconstructed networks represent the OTUs at 97\% identity, whereas the edges (that is, connections) correspond to a strong and significant (positive or negative) correlation between nodes. In order to describe the topology of the resulting networks, a set of measures (that is, number of nodes and edges, average path length, network diameter, cumulative degree distribution, clustering coefficient and modularity; Newman, 2003, 2006) was calculated and networks were visualized using the interactive platform Gephi (Bastian et al., 2009).

\section{Data analyses}

All measured physicochemical parameters were checked for normality and further log transformed, except soil $\mathrm{pH}$, before analyses. To test the influence of soil physicochemical parameters (environmental factors) on community structure, forward selection was used on redundancy analysis to select a combination of environmental variables that explained most of the variation observed in the bacterial 16S rRNA gene matrix. For that, a series of constrained redundancy analysis permutations was performed in Canoco (version 4.0 for Windows, PRI
Wageningen, Wageningen, The Netherlands) to determine which variables best explained the assemblage's variation, using manual forward selection and Monte-Carlo permutations tests (permutations $=999$ ). The ordination in $\mathrm{x}$ - and y axis and the length of the corresponding arrows indicated the relative importance of the physicochemical factor explaining the taxon distribution across communities.

To assess the temporal variation in the phylogenetic $\beta$-diversity among different time points within each stage of succession, we used permutational multivariate analysis of variance (PerMANOVA; Clarke and Gorley, 2006). Permutational multivariate analysis of variance was performed using sampling month as the main factor, allowing for full permutation of the raw data with Monte-Carlo tests accounting for type III error, where the fixed effects sum to zero with 9999 permutations. Changes in $\beta$-diversity within sites across different sampling time (using May as the baseline) were calculated as the difference, in percentage, between the average monthly weighted UniFrac distances (Lauber et al., 2013).

\section{Results}

\section{Site characteristics}

The selected sites were sampled four times over a 1-year period. This temporally and spatially explicit sampling scheme captured a wide range of physical and chemical gradients in the salt marsh ecosystem (Supplementary Figure S1 and Supplementary Table S1). In brief, the initial stages (0 and 5 years) were characterized by bare sand and bare sand covered with initial (clay/organic particle) sedimentation, respectively. These two sites revealed low nutrient contents $\left(\mathrm{OM}, \mathrm{N}^{-\mathrm{NH}_{4}^{+}}, \mathrm{N}^{-\mathrm{NO}_{3}^{-}}\right.$and S-SO $\mathrm{S}_{4}$ ), above-neutral $\mathrm{pH}$ (averages 8.7 and 8.3, respectively) and low salinity (measured as the concentration of sodium, expressed in $\mathrm{mg} \mathrm{dm}^{-3}$ ). With progressive succession and sedimentation caused by the dynamics of the tide, the marsh slowly increases in elevation, revealing a progressive increase in the level of silt and clay particles, as well as nutrients. In effect, a sandy soil progressively turns into a more loamy soil. The collective effects were found to gradually modify the physicochemical structure and composition of the salt marsh. Moreover, the $\mathrm{pH}$ was found to decrease to 7.4 at late succession, whereas salinity increased over time, owing to a cumulative effect, reaching up to $\sim 4000$ to $\sim 6000 \mathrm{mg} \mathrm{dm}^{-3}$ at late successional stages. For detailed description of the metadata, see Supplementary Table S1.

\section{Abundance of bacterial communities along the salt marsh chronosequence \\ Quantitative PCR was used to estimate the number of bacterial 16S rRNA gene copies in all stages of soil succession over the four sampling times. Reactions were performed in duplicates for all triplicate plots in each site, $E=102.57 \%$ and $r^{2}=0.99$. Within each}


site, no temporal variations in the bacterial abundances were observed within the year 2012 $(P>0.05)$. However, along the chronosequence, bacterial abundances revealed a small, but significant increase from 0 to 5 years (average log values of 9.39-9.95; $P<0.001$ ), with $\sim 10$-fold increases from 5 to 35 years (average log values of 9.95-10.76; $P<0.001)$; remaining statistically stable thereafter (Figure 1a and Supplementary Figure S2a). Cubic regression was then used to describe the bacterial abundance increments through the course of succession $\left(P=0.0001, r^{2}=0.988\right.$; Figure 1a).

\section{$\alpha$-Diversity measurements}

We determined the community $\alpha$-diversities across the successional stages using the pyrosequencing data based on the $\mathrm{V} 4-\mathrm{V} 6$ regions of the bacterial $16 \mathrm{~S}$ rRNA gene. The rarefied 454 pyrosequencing data set at a depth of 2600 reads per sample were binned into 11093 different OTUs, of which $2.81 \%$ (encompassing 4389 OTUs) were singletons. On the basis of these, values for $\alpha$-diversity, including OTU richness, ChaoI and Shannon's indices and Faith's phylogenetic diversity, decreased significantly from the early to the latest stages of succession $(P<0.005)$, as observed by linear regressions (Figures 1b-e). Conversely, the OTU richness, ChaoI and Shannon's indices did not differ from the initial successional stage to the soil of up to 65 years (Supplementary Figures S2b,c and e). Faith's phylogenetic diversity measure showed a progressive decrease over the course of succession $(P<0.05$; Supplementary Figure S2d), indicating an effect of phylogenetic clustering of the communities along the chronosequence.

\section{Bacterial community composition}

The communities were predominantly (at all stages) composed of members of the phylum Proteobacteria (45.9 $\pm 7.0 \%$; mean \pm s.d.), followed by Bacteroidetes
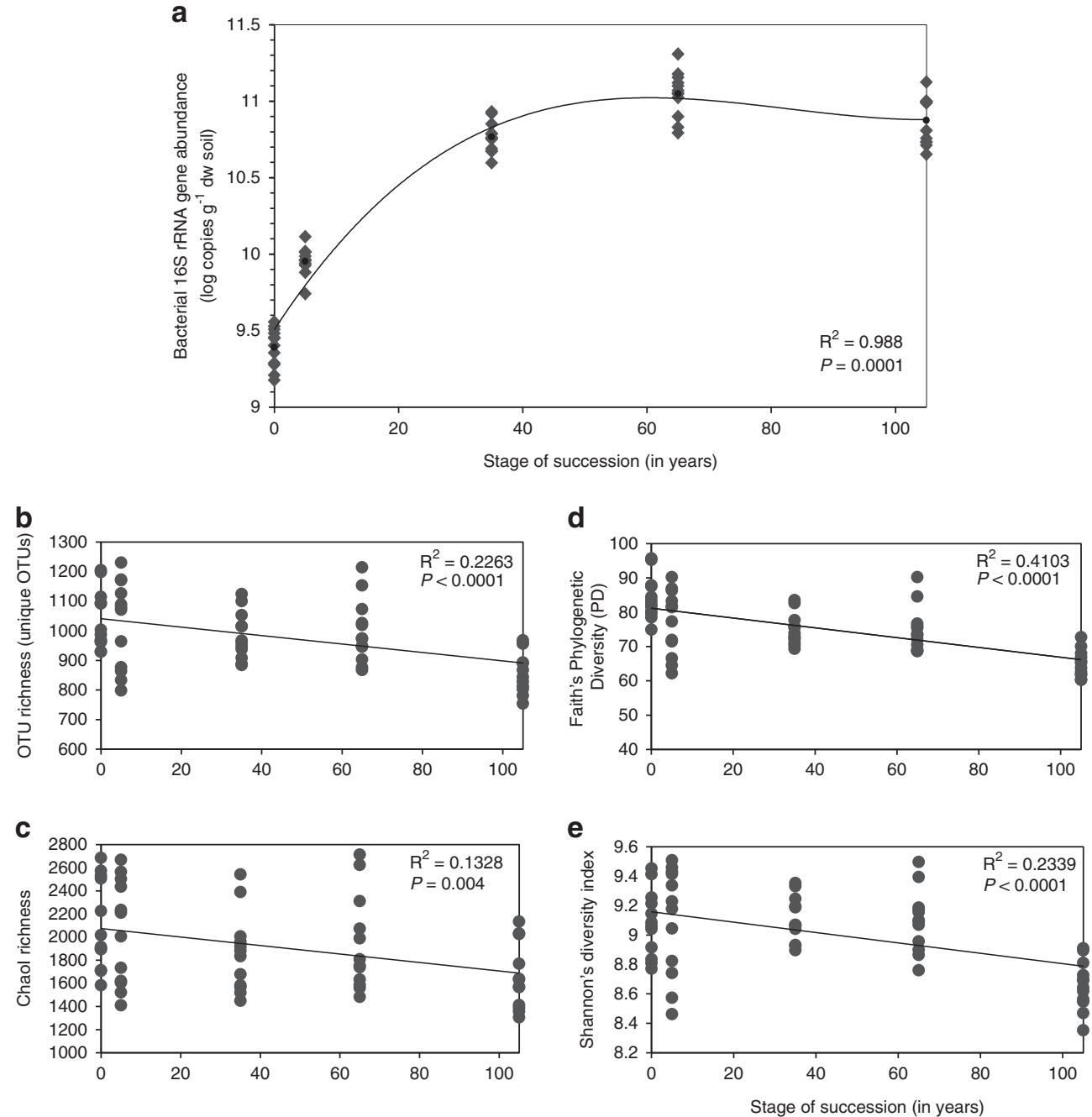

Figure 1 Bacterial abundance and $\alpha$-diversity measurements. (a) Cubic regression of bacterial abundances along the chronosequence, as indicated by log copy numbers of 16S rRNA gene per gram of dry-weight soil, using quantitative PCR. (b) Linear regression of OTU richness (count of unique OTUs at 97\% identity). (c) Linear regression of Chaol richness estimation. (d) Linear regression of Faith's phylogenetic diversity (PD), and (e) linear regression of Shannon's diversity index, along the chronosequence. 
$(15.6 \pm 7.0 \%)$. The relative abundance of Chloroflexi $(9.5 \pm 6.0 \%)$ increased linearly over the chronosequence, from $2.7 \pm 0.5 \%$ (stage 0 ) up to $17.9 \pm 3.1 \%$ (stage 105). Gemmatimonadetes $(2.0 \pm 0.7 \%)$ also progressively increased (from $1.5 \pm 0.3 \%$ at stage 0 up to $2.8 \pm 0.5 \%$ at stage 105). Conversely, Cyanobacteria $(1.5 \pm 1.5 \%)$ and Verrucomicrobia $(2.8 \pm 1.9 \%)$ showed an opposite pattern (decreasing steadily from $4.2 \pm 1.7 \%$ and $5.5 \pm 1.8 \%$ in soil at stage 0 to $0.1 \pm 0.1 \%$ and $1.3 \pm 0.3 \%$ in soil at stage 105 , respectively). The abundance of Firmicutes was low, accounting for $0.6 \pm 0.4$ of the relative abundance. Planctomycetes $(6.8 \pm 1.9 \%)$ showed hump-shaped curves, peaking at intermediate stage (stage 35), reaching up to $9.7 \pm 1.1 \%$. Acidobacteria and Actinobacteria showed non-significant regressions along the chronosequence. For the phylum Proteobacteria, we considered the relative abundance distributions at class level. Alphaproteobacteria $(18.8 \pm 3.2 \%)$ and Deltaproteobacteria $(9.0 \pm 1.7 \%)$ showed a hump-shaped distribution, peaking at intermediate stage (stage 35: $22.0 \pm 3.4 \%$ and $12.2 \pm 2.0 \%$, respectively). Conversely, Betaproteobacteria $(1.8 \pm 0.6 \%)$ and Gammaproteobacteria $(15.9 \pm 3.2 \%)$ showed the highest abundances at initial stage ( $4.5 \pm 2.3 \%$ and $23.2 \pm 5.5 \%$, respectively), decreasing progressively in later-stage soils (Figure 2c and Supplementary Figure S3).

\section{Phylogenetic $\beta$-diversity}

To assess the bacterial phylogenetic $\beta$-diversity we used Unifrac distances, which indicate the extent of the phylogenetic similarities among the bacterial communities (Lozupone and Knight, 2005). Principal coordinates analysis using UniFrac showed clear clustering of the bacterial communities in different stages of the chronosequence. Overall, these were phylogenetically more dissimilar between the successional stages than within the sites, irrespective of time of sampling. Although unweighted Unifrac principal coordinates analysis (total variation explained $21.2 \%$ ) could not distinguish between clusters obtained for communities in soils at stages 65 and 105 years, weighted UniFrac principal coordinates analysis (total variation explained $56 \%$ ) revealed a clearer difference between these clusters (Figure 2a). In addition, unweighted phylogenetic dissimilarities were higher in soils at initial successional stages ( 0 and 5 years), as the dots across triplicates and sampling times were less

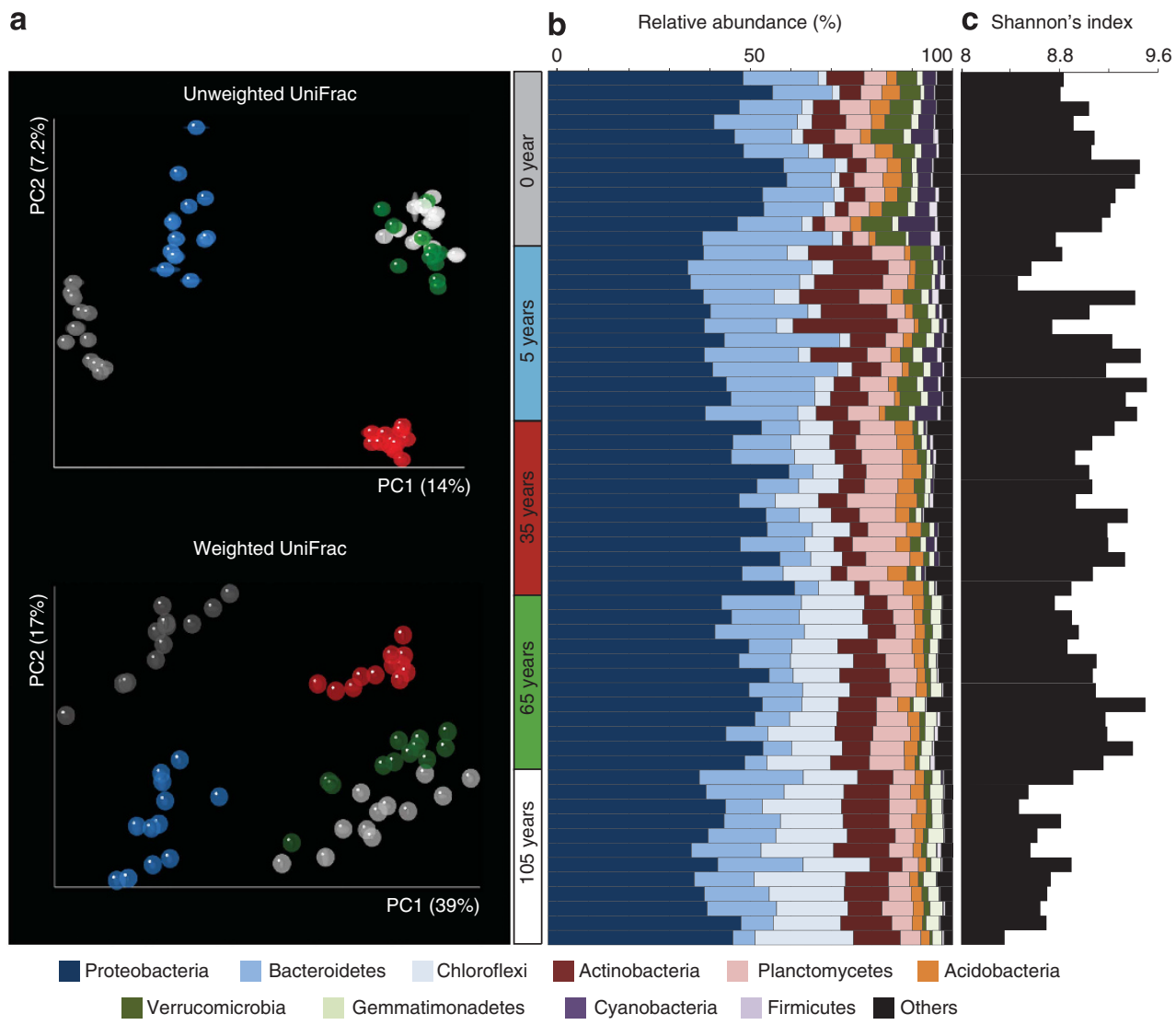

Figure 2 Phylogenetic $\beta$-diversity and bacterial taxonomic distribution. (a) Principal coordinate analysis of unweighted and weighted UniFrac distances of bacterial communities along succession. Samples' colour coding: grey, 0 years; blue, 5 years; red, 35 years; green, 65 years; white, 105 years. Ellipsoids around some samples represent jackknife variance for 10 times repeatedly resampling of a subset for each sample. (b) Bacterial community composition shown as relative abundance (\%) of taxa at the phylum level. Less abundant phyla (total average $<0.5 \%$ ) and unclassified bacteria were collapsed into 'others' bar. (c) Shannon's diversity index calculated individually for the complete time series presented as bar charts. 
clustered than those observed for other soil stages (Figure 2a), indicating higher phylogenetic turnover in species composition at these sites.

\section{Relationship between bacterial community} composition and environmental variables

To identify the potential effect of environmental factors on the bacterial community composition across the soils at different successional stages, we used forward selection on redundancy analysis. Overall, all measured parameters formed a clear gradient along the chronosequence (Figure 3). Despite the highly colinear profiles of the variables, individual selection of variables revealed, among the physical parameters measured, clay and sand content to be the major drivers influencing community composition $(F=31.24$ and $F=10.95$, respectively, $P=0.001)$. Among the chemical factors, $\mathrm{pH}$ $(F=12.40, P=0.001)$, salinity $(F=4.16, P=0.008)$ and sulphate content $(F=3.41, P=0.017)$ were major drivers, whereas other variables (that is, total $\mathrm{N}, \mathrm{N}-\mathrm{NH}_{4}^{+}, \mathrm{N}_{-} \mathrm{NO}_{3}^{-}$and $\mathrm{OM}$ ) revealed weaker effects on the bacterial assemblages (Figure 3). Collectively, we found that the physicochemical environment significantly explained the patterns of community composition (total variation explained $84.5 \%$ ), with clay content, salinity and $\mathrm{pH}$ together accounting for $83.3 \%$ of the explained variation. In addition, the

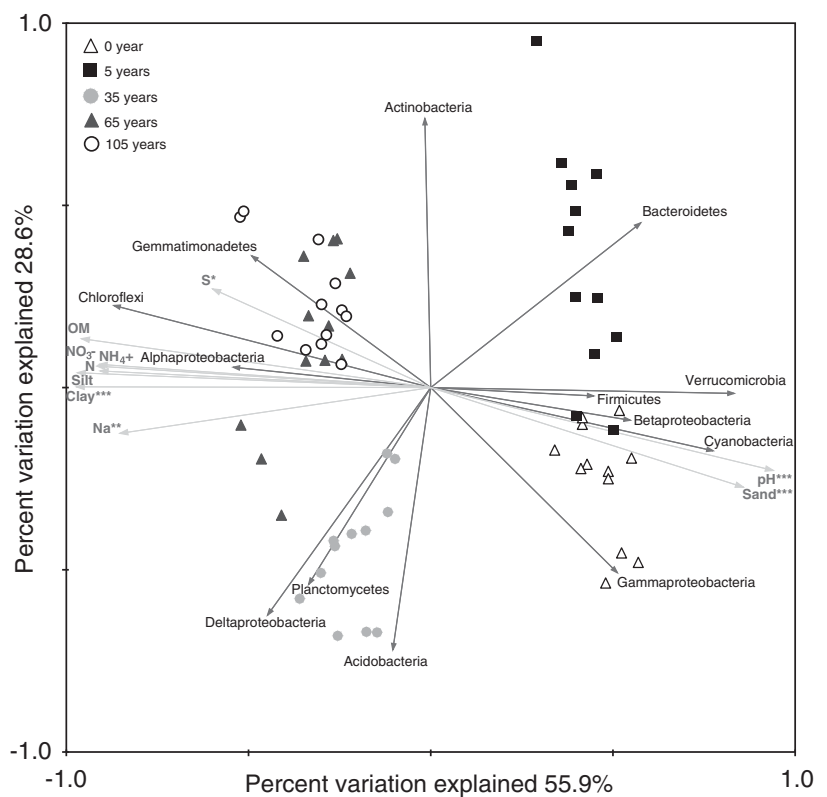

Figure 3 Redundancy analysis of the effect of soil parameters (environmental factors; dark arrow) on bacterial taxonomic distribution (grey arrows). Taxonomic information is shown at the phylum level, except for the phylum Proteobacteria, at the class level. Numbers in brackets indicate the percentage of the total variance explained by the axis. Physicochemical parameters with significant effects are shown as ${ }^{*} P<0.05$, ${ }^{*} P<0.01$ and $* *{ }^{*} P=0.001$ (999 times Monte-Carlo permutation test). Only taxa above $0.5 \%$ at total average abundance are shown. magnitude of individual environmental variables on taxon distributions was also tested by Spearman correlations. We found the phyla Verrucomicrobia, Cyanobacteria, Bacteroidetes, Firmicutes and the classes Beta- and Gammaproteobacteria to be strongly correlated with characteristics prevailing at the initial successional stages (sandy soil under low salinity and nutrient content), whereas the phyla Chloroflexi, Gemmatimonadetes, Actinobacteria and the classes Alpha- and Deltaproteobacteria were correlated with factors prevailing at late succession $(P<0.01)$. Similarly, insignificant correlations were found for the environmental variables tested versus the phyla Planctomycetes and Acidobacteria, except for a weak correlation between Planctomycetes and salinity (Figure 3 and Supplementary Figure S4).

Temporal variations in phylogenetic $\beta$-diversity within each stage of succession

PerMANOVA analyses of weighted UniFrac distances revealed significant differences $(P<0.001)$ among sampling times, which were strongest in soils of early succession: stage 0 (pseudo- $F=2.63$, $P<0.0001$ ) and stage 5 (pseudo- $F=2.76, P<0.0001$ ). In contrast, soils of intermediate and late succession showed no significant changes in community turnover over time (stage 35 (pseudo- $F=1.26$, $P=0.1274$ ); stage 105 (pseudo- $F=1.25, P=0.2162$ )). An exception was observed at stage 65 (pseudo$F=3.27, P=0.0018$ ). The latter finding could be ascribed to differences observed in the samples collected in May, which clustered separately from the other samples within this site (Supplementary Figure S5). Different from the initial stages of soil succession (stages 0 and 5 ), temporal variation detected at stage 65 was mostly related to shifts in the relative OTU abundances, that is, community evenness rather than phylogenetic turnover in species composition, as observed by differences in weighted and unweighted Unifrac clusters (Figure 2a). Regarding environmental parameters, the successional stages 0 and 5 years showed significant increases in salinity from samples MayJuly to September-November (Supplementary Table S1). Although these increases did not correlate with the temporal differences detected at stage 0 , at stage 5 , the effect of salinity was significant $(F=4.66, \quad P=0.008)$. At stage 65 , the observed differences were significantly correlated with changes in the $\mathrm{N}^{-\mathrm{NO}_{3}^{-}}$content $(F=5.94, P=0.001)$.

Consistency in phylotype co-occurrence within sites throughout the chronosequence

We generated co-occurrence networks individually for each stage of succession (Figure 4). Following this, we calculated the topological properties of the obtained networks to distinguish differences in OTU correlations over succession. Considering the number of correlations (including both positive and negative ones), the highest values were 


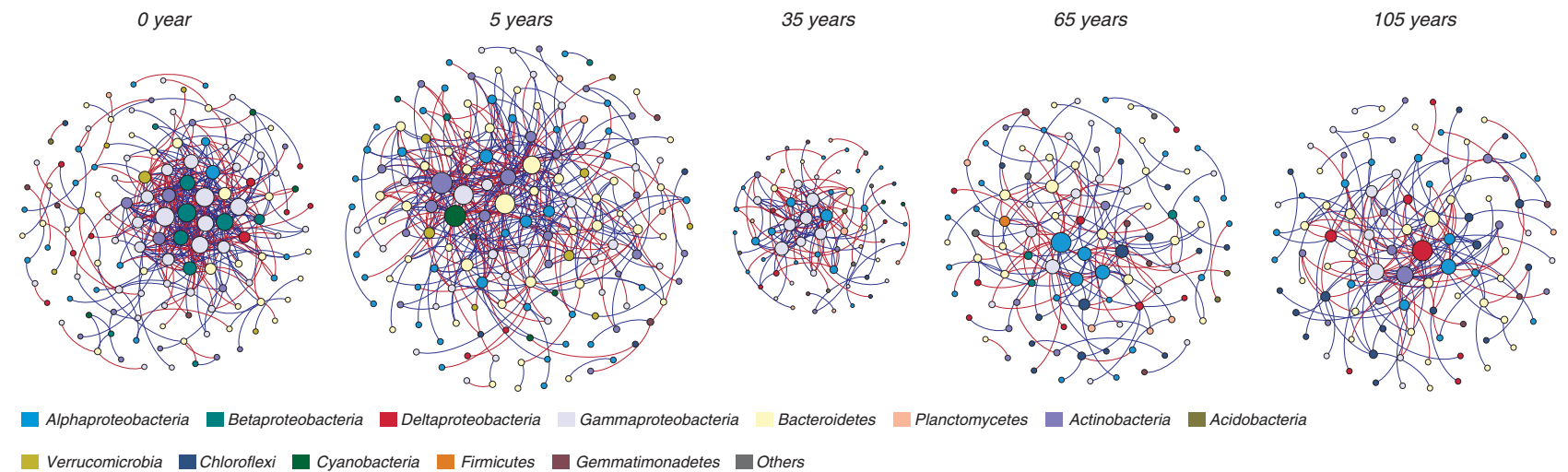

Figure 4 Network co-occurrence analysis of bacterial communities along succession. Each dot represents a bacterial phylotype (an OTU clustered at 97\%). A connection stands for SparCC correlation with a magnitude $>0.6$ (positive correlation-blue edges) or $<-0.6$ (negative correlation-red edges) and statistically significant $(P<0.01)$. The size of each node is proportional to the number of connections (that is, degree). Each node was labelled at the phylum level, except for the phylum Proteobacteria, shown at the class level.

observed in the communities from soil at the initial stages ( 0 and 5 years), whereas the lowest value was observed at stage 35 . Stage 0 presented the highest node connectivity (that is, average degree of 2.919). The average network distance between all pairs of nodes was variable all over the chronosequence (that is, average path length ranging from 1.663 edges at the stage 35 up to 2.425 edges at stage 5). The diameters of the networks (that is, the longest distance) followed a similar trend, peaking at stage 5 (reaching a diameter of 6 edges) and presenting the lowest value at stage 35 (3 edges). Overall comparison of the network topologies showed initially complex networks (stages 0 and 5), with approximately twofold higher correlations than networks at intermediate (stage 35 ) and late successional stages (stages 65 and 105; Figure 4 and Table 1).

\section{Discussion}

A comprehensive assessment of bacterial community succession along a salt marsh chronosequence Macro-ecologists have recently debated how chronosequences of land development can be of use to understand historical ecological successions (see Walker et al., 2010), and the importance of studying low-disturbance sites has been brought forward. In this context, we focused on the diversity and composition of bacterial assemblages along an undisturbed salt marsh gradient, containing soils spanning more than 100 years of ecosystem development. This ecosystem offers a unique dynamic landscape to investigate the patterns of microbial community succession. This salt marsh chronosequence is initially characterized by a marine coastal (brown) food web under daily marine/tide influence that develops towards a terrestrial (green) food web. Although several earlier studies investigated microbial community successions along environmental chronosequences (Nemergut et al., 2007; Brankatschk et al., 2011), the processes leading to the observed patterns have hardly been addressed, mostly because of a lack of comprehensive measurement of ecosystem variables and repeatable trajectories. We bypassed these drawbacks by studying a long-term salt marsh gradient, the permanent experimental plots of which have been monitored for over 20 years (Van Wijnen et al., 1997), and by gathering a large data set of biological, chemical and physical parameters.

In previous studies (Horner-Devine et al., 2004; Córdova-Kreylos et al., 2011), salt marsh inhabiting bacterial communities were described at deep sequencing resolution (Bowen et al., 2012) and at continental scales (Martiny et al., 2011). Moreover, their response to external nutrients has been recorded (Bowen et al., 2009). These communities were postulated to serve critical functions, such as protection of the coast from human influences (Valiela and Cole, 2002) and carrying out key geochemical processes responsible for ecosystem functioning (Lage et al., 2010). Also, as indicated by Lozupone and Knight (2007), the phylogenetic diversity of these communities even transcended that of other species-rich environments such as soils. Indeed, our current data reveal that all stages of succession had high levels of bacterial phylogenetic diversity and species richness. Regarding the total bacterial abundances, we observed that soils at intermediate and late stages of the salt marsh chronosequence presented even higher levels than those described in agricultural soils in the Netherlands (Pereira e Silva et al., 2012). Strikingly, we observed that the bacterial communities found at the initial successional stage, characterized by bare and infertile sandy soils, had higher phylogenetic diversity than those found at intermediate and later stages of soil succession (presenting higher OM, plant diversity and abundance), despite their relatively low bacterial abundance. Phylogenetic diversity has been suggested as a powerful proxy for assessing the role of diversity in ecosystem functioning, as it takes into account (phylogenetically linked) ecological differences between species (Srivastava et al., 2012). 
Table 1 Topological properties of networks obtained within each stage of succession

Network metrics

Stage of succession (in years)

\begin{tabular}{ccccc}
\hline 0 & 5 & 35 & 65 & 105 \\
\hline 135 & 155 & 72 & 108 & 101 \\
394 & 379 & 136 & 156 & 176 \\
218 & 221 & 78 & 93 & 112 \\
176 & 158 & 58 & 63 & 64 \\
1.99 & 2.425 & 1.663 & 2.14 & 2.232 \\
5 & 6 & 3 & 5 & 5 \\
0.164 & 0.131 & 0.127 & 0.06 & 0.103 \\
3.794 & 2.635 & 1.652 & 2.302 & 1.636 \\
2.919 & 2.445 & 1.889 & 1.444 & 1.743 \\
& & & &
\end{tabular}

All properties were measured using the interactive platform Gephi (Bastian et al., 2009).

${ }^{a}$ Number of OTUs with at least one correlation $>0.6$ or $<-0.6$ and statistically significant $(P<0.01)$.

bNumber of connections; number of strong and significant correlations between nodes.

'Correlation magnitude $>0.6(P<0.01)$.

${ }^{\mathrm{d}}$ Correlation magnitude $<-0.6(P<0.01)$.

${ }^{e}$ Average network distance between all pairs of nodes. It indicates the number of steps one needs to make on average in the graph in order to connect two randomly selected nodes (Newman, 2003).

${ }^{\mathrm{f}}$ The longest distance between the nodes that exists in the network (measured in edges; Newman, 2003).

sHow nodes are embedded in their neighbourhood, and thus the degree to which they tend to cluster together.

${ }^{h}$ Modularity $>0.4$ indicates that the partition produced by the modularity algorithm can be used to detect distinct communities within the network. It indicates that there are nodes in the network that are more densely connected between each other than with the rest of the network and that their density is noticeably higher than the graph's average (Newman, 2006).

${ }^{i}$ Node connectivity; shows how many connections (on average) each node has to another unique node in the network.

Thus, if we consider that bacterial traits show phylogenetic signals, these results can be used as a proxy of the functional trait space of a community.

The high complexity of the bacterial communities present in the initial stages of salt marsh development, as indicated by the high Faith's phylogenetic diversity, could be explained by the intrinsically high and stochastic microbial influx owing to marine input, incited by the tidal regime (that is, high immigration rates) followed by establishment and persistence, if only at levels of low activity. In this sense, the initial stages of salt marsh development are naturally and regularly subjected to invasion by (and establishment of) diverse marine bacteria. This constant input of different microorganisms, followed by differential establishment, is likely to be at the basis of the observed diversity. The high degree of dissimilarity between the communities from 0 and 5 years of succession, both subjected to flooding twice daily, and the lower temporal variability observed at later stages of succession, support this contention. In addition to the high rates of microbial influx, the observed patterns in community composition at the beginning of the chronosequence might also lie in partial colonization by microbial mats, of which the occurrence and distribution is unpredictable throughout the year. Although microbial mats have key roles in initial ecosystem development, enriching the system with organic carbon and other compounds, it has been suggested that the local conditions (frequent wet/dry cycles, input of diverse nutrient sources, colonization by diverse organisms, including primary producers) may incite a high degree of temporal variability, resulting in mat occurrence and composition being erratic over time (Bolhuis and Stal, 2011). Moreover, when examining the composition of these microbial mats, Bolhuis and Stal (2011) found a relatively high bacterial diversity within the mats, even among mats along a spatial transect. Although microbial mat structures were not the main focus of this study, we observed that autotrophic bacteria (mostly Cyanobacteria) exhibited higher occurrence in soils from initial succession ( 0 and 5 years), exceeding the values observed at later stages. This phylum encompassed mostly the orders Nostocales, Stigonematales, Oscillatoriales and Chroococcales, in agreement with the groups commonly found in microbial mats, as previously reported (Bolhuis and Stal, 2011).

\section{Integrating bacterial communities into the study of ecological succession}

Succession in a particular environment assumes, by definition, that communities change over time in an orderly manner (Begon et al., 1996; Brown and Lomolino, 1998). Although macro-ecologists have been shifting away from the standardized description of vegetation patterns to focus on processes underpinning such patterns and community dynamics (that is, moisture-nutrient gradients, dispersion and ecological interactions among individuals, such as competition, predation and facilitation), microbial ecologists still lack a well-established and suitable framework to properly include microbes into the studies of succession (Fierer et al., 2010). In this context, our results contribute to the better understanding of the patterns of bacterial succession by, for instance, showing that certain phyla, such as Verrucomicrobia, Chloroflexi and Cyanobacteria, had clear trends along the 
gradient. Moreover, the relative abundance of some bacterial groups was highly correlated with the reigning environmental parameters. For instance, Cyanobacteria and Verrucomicrobia responded to higher levels of sand and $\mathrm{pH}$, whereas Chlorofexi and Alphaproteobacteria were positively correlated with nitrogen concentrations and $\mathrm{OM}$ depositions. Together, these findings suggest a high ecological coherence of certain bacterial groups even at a high taxonomic ranks (as previously reported, Philippot et al., 2010), ultimately elucidating the eco-evolutionary trajectory of bacterial assemblages along the chronosequence.

Temporal variation in phylogenetic $\beta$-diversity (that is, phylogenetic turnover), a crucial aspect of microbial communities that is often overlooked, can be elucidated by using a succession framework. Here, we provide evidence for an intricate bacterial phylogenetic turnover pattern, which was higher in the initial stages of succession ( 0 and 5 years, higher turnover in species composition), confirming our hypothesis. The high variations in phylogenetic $\beta$-diversity found at these stages could be explained by the temporal variability in nutrients as well as immigration (mostly because of external marine nutrient and microbial input, respectively), and a higher amplitude of variation in environmental conditions (for example, salinity, oxygen and temperature) at poorly vegetated sites. As succession proceeds, the buffering effects of soil as well as plants became more dominant, possibly reducing the amplitudes of variation and resulting in lowered phylogenetic turnover. In this context, it is suggested that the bacterial communities at the late stage of succession reached the steady-state 'climax' stage in which communities are in equilibrium with the local environment. In fact, owing to the intrinsic nature of salt marshes, such a state is not to be regarded as completely static. We thus observed a temporal effect at stage 65 , due to shifts in relative abundance, which were correlated with the $\mathrm{N}-\mathrm{NO}_{3}^{-}$ content in the samples collected in May. This stage is also characterized by a peak in plant diversity (Schrama et al., 2012), suggesting a possible role of plant phenology in regulating the observed variation. Remarkably, the 'diversity begets diversity' theorem (Whittaker, 1972), which assumes that a community develops towards species complexity, is not true in this case. In fact, here we present an alternative, where such a 'climax' state can be composed of a phylogenetically less diverse community than that observed at primary succession (Figure 1d and Supplementary Figure S2d), with a progressive clustering over time.

Understanding microbial community succession-an interwoven web of biotic and abiotic variables

Linking population dynamics to environmental conditions is crucial to address how the edges of population ranges are delineated (Holt et al., 2005).
This linkage may provide insights into how abiotic variables influence the composition and distribution of taxa along gradients (that is, allogenic processes), apart from neutral processes (see Chase (2003); Ferrenberg et al. (2013)). In this study, we supply data concerning taxon distributions across our system. Major roles are ascribed to the physical structure (clay and sand content), salinity and $\mathrm{pH}$ as the drivers of the observed distribution. Soil $\mathrm{pH}$ has been recognized as a strong factor shaping bacterial taxon distributions (Fierer and Jackson, 2006; Lauber et al., 2009), whereas salinity (Lozupone and Knight, 2007; Wang et al., 2011) and soil structure (Pereira e Silva et al., 2012; Lauber et al., 2013) are also known to have important roles. These findings corroborate our initial hypothesis that, in fact, the differential distribution of abiotic drivers along the chronosequence has major roles in bacterial community establishment and succession.

In addition to be driven by abiotic parameters, succession of microbial communities is thought to be partially autogenic (Archer et al., 1988; Walker and del Moral, 2003), indicating that the interwovenness of populations within a community can alter the physical and chemical characteristics of the surroundings. This possibly affects secondary colonizing species through competition for nutrients, antagonism or facilitation. Such a process occurs in microbial mats (Schütte et al., 2009), where nitrogen fixed by Cyanobacteria introduces ammonia into the system, creating favourable conditions for other organisms to grow. Thus, this is possibly extendible to other ecological interpretations concerning niche occupancy and functional interdependencies within a community. Despite the importance of biotic interactions at initial stages of salt marsh development (Bolhuis and Stal, 2011), we found no evidence that would suggest biotically-driven community succession played a role. Specifically, the comparison of network topologies between closelyrelated sites along the chronosequence revealed no clear pattern of modules evolving over time. The latter could have indicated co-occurrence due to interactions between bacterial species, as similar species patterns would have arisen under different environmental filters. Biotically-driven succession has been suggested as a transitory mechanism by which communities are structured at small time scales. This was proposed for bacterioplankton community assembly in lakes, where slight shifts in environmental variables inhibit particular modules from evolving through time, even over short time frames (Eiler et al., 2012).

\section{Phylotype co-occurrence and niche partitioning}

Network topology allows us to focus on the patterns of relations within a given ecosystem, and might provide evidence of how these patterns affect ecosystem properties (Cumming et al., 2010). For instance, it has been shown that the complexity of 
ecological networks increases along successional gradients, leading to greater stability of the food web, which is explained by the strength of the interactions between predator and prey (Neutel et al., 2007). In co-occurrence networks, the presence and distribution of modules within a network serve as proxies for the study of niche partitioning and synergistic relationships (Chaffron et al., 2010; Barberán et al., 2012). Thus, during ecological successions, an increase in productivity is expected to promote community complexity, which should be translated into networks with higher numbers of modules characterized by well-connected groups of nodes. However, we observed the opposite pattern, that is, a decrease in network complexity, as indicated by a reduction in network edges, towards the intermediate and later stages of succession. On the basis of these results, we propose that temporal variability in community composition is likely to be the major mechanism underpinning the observed configurations. This is based on the observations that the communities presenting higher phylotype co-occurrence were those in which we detected temporal turnover in phylogenetic species composition (stages 0 and 5; Figure 4 and Table 1). In this context, we posit that strong environmental dynamics associated with the tidal regime at initial succession generates daily fluctuations in oxygen, temperature and water saturation/salinity, leading to temporally-driven niche partitioning, which, combined with high immigration as well as persistence (colonization) rates, may elicit high phylotype coexistence. These complex and phylogenetically divergent bacterial communities were, in turn, fuelled by the constant flow of nutrients of marine origin. Thus, temporal niche partitioning, a wellknown process in macro-ecology, represents a plausible mechanism that promotes phylotype coexistence in the complex bacterial communities in the early successional stage samples. Efforts in reconstructing community networks by aggregating temporal effects, different localities and environmental gradients, have been currently suggested as a sophisticated way to study the progression of communities in natural systems (Poisot et al., 2012). By tracking the network dynamics along an environmental chronosequence, we challenge our initial hypothesis by showing that the spatial niche distribution, expected to be higher in soils at late than initial succession, is not an overwhelming mechanism promoting phylotype coexistence. In fact, we suggest the great dynamism in environmental conditions observed at the initial stage of salt marsh succession to be the main mechanism promoting the emergence of multiple niches over short periods of time (that is, temporal niche partitioning). Thus, temporal partitioning at the early stages is hypothesized to incite elevated levels of phylotype coexistence, outpacing even the degree to which spatial partitioning acts. The latter is likely to have been dominant at the later successional stages.

\section{Conflict of Interest}

The authors declare no conflict of interest.

\section{Acknowledgements}

We thank the anonymous reviewers for their constructive remarks in the previous version of this manuscript. We are grateful to Maarten Schrama, Han Olff and Ruth Howison for information on sampling locations and valuable discussions. We acknowledge Jolanda K Brons for helping in sampling expeditions and data collection, and Fernando Dini Andreote for assisting soil physicochemical analysis and valuable comments on the manuscript. We also acknowledge Jonathan Friedman and Bob Dröge for bioinformatics and computational support. We thank the 'Nederlandse Vereniging voor Natuurmonumenten' for granting us access to the salt marsh. This research was supported by the Netherlands Organisation for Scientific Research (NWO).

\section{References}

Archer S, Scifres C, Bassham CR, Maggio R. (1988). Autogenic succession in a subtropical savanna: conversion of grassland to thorn woodland. Ecol Monogr 58: 111-127.

Bach HJ, Tomanova J, Schloter M, Munch JC. (2002). Enumeration of total bacteria and bacteria with genes for proteolytic activity in pure cultures and in environmental samples by quantitative PCR mediated amplification. J Microbiol Methods 49: 235-245.

Barberán A, Bates ST, Casamayor EO, Fierer N. (2012). Using network analysis to explore co-occurrence patterns in soil microbial communities. ISME $J$ 6: 343-351.

Bastian M, Heymann S, Jacomy M. (2009). Gephi: An Open Source Software For Exploring and Manipulating Networks International AAAI Conference on Weblogs and Social Media. San Jose, CA, USA.

Bates ST, Berg-Lyons D, Caporaso JG, Walters WA, Knight R, Fierer N. (2011). Examining the global distribution of dominant archaeal populations in soil. ISME J 5: 908-917.

Begon M, Harper JL, Townsend CR. (1996). Ecology: Individuals, Populations and Communities. Blackwell Science: Cambridge, UK.

Bolhuis H, Stal LJ. (2011). Analysis of bacterial and archaeal diversity in coastal microbial mats using massive parallel 16S rRNA gene tag sequencing. ISME J 5: 1701-1712.

Bormann BT, Sidle RC. (1990). Changes in productivity and distribution of nutrients in a chronosequence at Glacier Bay National Park, Alaska. J Ecol 78: 561-578.

Bowen JL, Crump BC, Deegan LA, Hobbie JE. (2009). Salt marsh sediment bacteria: their distribution and response to external nutrient inputs. ISME $J$ 3: 924-934.

Bowen JL, Morrison HG, Hobbie JE, Sogin ML. (2012). Salt marsh sediment diversity: a test of the variability of the rare biosphere among environmental replicates. ISME J 6: 2014-2023.

Brankatschk R, Töwe S, Kleineidam K, Schloter M, Zeyer J. (2011). Abundances and potential activities of nitrogen cycling microbial communities along 
a chronosequence of a glacier forefield. ISME $J \mathbf{5}$ : 1025-1037.

Breen K, Lévesque E. (2006). Proglacial succession of biological soil crusts and vascular plants: biotic interactions in the High Arctic. Can J Bot 84: 1714-1731.

Brown JH, Lomolino MV. (1998). Biogeography, 2nd edn Sinauer Associates: Sunderland, MA, USA

Caporaso JG, Bittinger K, Bushman FD, DeSantis TZ, Andersen GL, Knight R. (2010a). PyNAST: a flexible tool for aligning sequences to a template alignment. Bioinformatics 26: 266-267.

Caporaso JG, Kuczynski J, Stombaugh J, Bittinger K, Bushman FD, Costello EK et al. (2010b). QIIME allows analysis of high-throughput community sequencing data. Nat Methods 7: 335-336.

Chaffron S, Rehrauer H, Pernthaler J, Von Mering C. (2010). A global network of coexisting microbes from environmental and whole-genome sequence data. Genome Res 20: 947-959.

Chapin FS, Walker LR, Fastie CL, Sharman LC. (1994). Mechanisms of primary succession following deglaciation at Glacier Bay, Alaska. Ecol Monogr 64: 149-175.

Chase JM. (2003). Community assembly: when should history matter? Oecologia 136: 489-498.

Clarke KR, Gorley RN. (2006). PRIMER, 6th edn. PRIMERE Ltd.: Plymouth, UK.

Clements F. (1916). Plant Succession: An Analysis of the Development of Vegetation. Carnegie Institute: Washington DC, USA.

Cumming GS, Bodin Ö, Ernstson H, Elmqvist T. (2010). Network analysis in conservation biogeography: challenges and opportunities. Divers Distrib 16: 414-425.

Córdova-Kreylos AL, Cao Y, Green PG, Hwang H-M, Kuivila KM, LaMontagne MG et al. (2006). Diversity, composition, and geographical distribution of microbial communities in California salt marsh sediments. Appl Environ Microbiol 72: 3357-3366.

DeBruyn JM, Nixon LT, Fawaz MN, Johnson AM, Radosevich M. (2011). Global biogeography and quantitative seasonal dynamics of gemmatimonadetes in soil. Appl Environ Microb 77: 6295-6300.

Deiglmayr K, Phillippot L, Tscherko D, Kandeler E. (2006). Microbial succession of nitrate-reducing bacteria in the rhizosphere of Poa alpina across a glacier foreland in the Central Alps. Environ Microbiol 8: 1600-1612.

DeSantis TZ, Hugenholtz P, Larsen N, Rojas M, Brodie EL, Keller K et al. (2006). Greengenes, a chimera-checked $16 \mathrm{~S}$ rRNA gene database and workbench compatible with ARB. Appl Environ Microbiol 72: 5069-5072.

Edgar RC. (2010). Search and clustering orders of magnitude faster than BLAST. Bioinformatics 26: 2460-2461.

Eiler A, Heinrich F, Bertilsson S. (2012). Coherent dynamics and association networks among lake bacterioplankton taxa. ISME J 6: 330-342.

Elhottová D, Szili-Kovács T, Tř́íska J. (2002). Soil microbial community of abandoned sand fields. Folia Microbiol 47: 435-440.

Ferrenberg S, O’Neill SP, Knelman JE, Todd B, Duggan S, Bradley D et al. (2013). Changes in assembly processes in soil bacterial communities following a wildfire disturbance. ISME J 7: 1102-1111.

Fierer N, Jackson RB. (2006). The diversity and biogeography of soil bacterial communities. Proc Natl Acad Sci USA 103: 626-631.

Fierer N, Nemergut D, Knight R, Craine JM. (2010). Changes through time: integrating microorganisms into the study of succession. Res Microbiol 161: 635-642.
Friedman J, Alm EJ. (2012). Inferring correlation networks from genomic survey data. PLoS Comput Biol 8: e1002687.

Grime JP. (2001). Plant Strategies, Vegetation Processes, and Ecosystem Properties. John Wiley and Sons: New York, NY, USA.

Haas BJ, Gevers D, Earl AM, Feldgarden M, Ward DV, Giannoukos G et al. (2011). Chimeric 16S rRNA sequence formation and detection in Sanger and 454-pyrosequenced PCR amplicons. Genome Res 21: 494-504.

Hodkinson ID, Coulson SJ, Webb NR. (2003). Community assembly along proglacial chronosequences in the high Arctic: vegetation and soil development in northwest Svalbard. J Ecol 91: 651-663.

Holt RD, Keitt TH, Lewis MA, Maurer BA, Taper ML. (2005). Theoretical models of species' borders: single species approaches. Oikos 108: 18-27.

Horner-Devine MC, Lage M, Hughes JB, Bohannan BJM. (2004). A taxa-area relationship for bacteria. Nature 432: 750-753.

Hüttl RF, Weber E. (2001). Forest ecosystem development in post-mining landscapes: a case study of the Lusatian lignite district. Naturwissenschaften $\mathbf{8 8}$ : 322-329.

Ives AR, Dennis B, Cottingham K, Carpenter SR. (2003). Estimating community stability and ecological interactions from time-series data. Ecol Monogr 73: 301-330.

Johnson EA, Miyanishi K. (2008). Testing the assumptions of chronosequences in succession. Ecol Lett 11: 419-431.

Johnson EA. (1979). Succession an unfinished revolution. Ecology 60: 238-240.

Keeney DR, Nelson DW. (1982). Nitrogen-inorganic forms. In: Page AL, Miller RH, Keeney DR (eds). Methods of Soil Analysis: Part 2, 2nd edn. Agron Monogr 9. ASA and SSSA: Madison, WI, USA, pp 643-698.

Kozdrój J, van Elsas JD. (2001). Structural diversity of microbial communities in arable soils of a heavily industrialised area determined by PCR-DGGE fingerprinting and FAME profiling. Appl Soil Ecol 17: 31-42.

Kuramae EE, Gamper HA, Yergeau E, Piceno YM, Brodie EL, Desantis TZ et al. (2010). Microbial secondary succession in a chronosequence of chalk grasslands. ISME J 4: 711-715.

Lage MD, Reed HE, Weihe C, Crain CM, Martiny JB. (2010). Nitrogen and phosphorus enrichment alter the composition of ammonia-oxidizing bacteria in salt marsh sediments. ISME J 4: 933-494.

Lauber CL, Hamady M, Knight R, Fierer N. (2009). Pyrosequencing-based assessment of soil $\mathrm{pH}$ as a predictor of soil bacterial community composition at the continental scale. Appl Environ Microbiol 75: 5111-5120.

Lauber CL, Ramirez KS, Aanderud Z, Lennon J, Fierer N. (2013). Temporal variability in soil microbial communities across land-use types. ISME J 7: 1641-1650.

Lipson DA. (2007). Relationships between temperature responses and bacterial community structure along seasonal and altitudinal gradients. FEMS Microbiol Ecol 59: 418-427.

Liu Z, Lozupone C, Hamady M, Bushman FD, Knight R. (2007). Short pyrosequencing reads suffice for accurate microbial community analysis. Nucleic Acids Res 35: e120.

Lockwood JL, Powell RD, Nott MP, Pimm SL. (1997). Assembling ecological communities in time and space. Oikos 80: 549-553. 
Lozupone C, Hamady M, Knight R. (2006). UniFrac-an online tool for comparing microbial community diversity in a phylogenetic context. BMC Bioinform 7: 371.

Lozupone C, Knight R. (2005). UniFrac: a new phylogenetic method for comparing microbial communities. Appl Environ Microbiol 71: 8228-8235.

Lozupone C, Knight R. (2007). Global patterns in bacterial diversity. Proc Natl Acad Sci USA 104: 11436-11440.

Martiny JB, Eisen JA, Penn K, Allison SD, Horner-Devine MC. (2011). Drivers of bacterial beta-diversity depend on spatial scale. Proc Natl Acad Sci USA 108: 7850-7854.

Nemergut DR, Anderson SP, Cleveland CC, Martin AP, Miller AE, Seimon A et al. (2007). Microbial community succession in an unvegetated, recently deglaciated soil. Microbiol Ecol 53: 110-122.

Neutel AM, Heesterbeek JA, van de Koppel J, Hoenderboom G, Vos A, Kaldeway C et al. (2007). Reconciling complexity with stability in naturally assembling food webs. Nature 449: 599-602.

Newman MEJ. (2003). The structure and function of complex networks. SIAM Rev 45: 167-256.

Newman MEJ. (2006). Modularity and community structure in networks. Proc Natl Acad Sci USA 103: 8577-8582.

Nicol GW, Tscherko D, Embley TM, Prosser JI. (2005). Primary succession of soil Crenarchaeota across a receding glacier foreland. Environ Microbiol 7: 337-347.

Olff H, De Leeuw J, Bakker JP, Platerink RJ, van Wijnen HJ. (1997). Vegetation succession and herbivory in a salt marsh: changes induced by sea level rise and silt deposition along an elevational gradient. J Ecol 85: 799-814.

Pereira e Silva MC, Dias AC, van Elsas JD, Salles JF. (2012). Spatial and temporal variation of archaeal, bacterial and fungal communities in agricultural soils. PLoS One 7: e51554.

Philippot L, Andersson SG, Battin TJ, Prosser JI, Schimel JP, Whitman WB et al. (2010). The ecological coherence of high bacterial taxonomic ranks. Nat Rev Microbiol 8: 523-529.

Poisot T, Canard E, Mouillot D, Mouquet N, Gravel D. (2012). The dissimilarity of species interaction networks. Ecol Lett 15: 1353-1361.

Preston FW. (1960). Time and space and the variation of species. Ecology 41: 611-627.

Price MN, Dehal PS, Arkin AP. (2009). FastTree: computing large minimum evolution trees with profiles instead of a distance matrix. Mol Biol Evol 26: 1641-1650.

Reeder J, Knight R. (2010). Rapid denoising of pyrosequencing amplicon data: exploiting the rank-abundance distribution. Nat Methods 7: 668-669.

Salles JF, van Elsas JD, van Veen JA. (2006). Effect of agricultural management regimes on Burkholderia community structure in soil. Microb Ecol 52: 267-279.

Schadt CW, Martin AP, Lipson DA, Schmidt SK. (2003). Seasonal dynamics of previously unknown fungal lineages in tundra soils. Science 301: 1359-1361.

Schmidt SK, Reed SC, Nemergut DR, Grandy AS, Cleveland CC, Weintraub MN et al. (2008). The earliest stages of ecosystem succession in high-elevation (5000 metres above sea level), recently deglaciated soils. Proc Biol Sci 275: 2793-2802.

Schrama M, Berg MP, Olff H. (2012). Ecosystem assembly rules: the interplay of green and brown webs during salt marsh succession. Ecology 93: 2353-2364

Schütte UM, Abdo Z, Bent SJ, Williams CJ, Schneider GM, Solheim B et al. (2009). Bacterial succession in a glacier foreland of the high Arctic. ISME $J$ 3: 1258-1268.

Sigler WV, Zeyer J. (2002). Microbial diversity and activity along the forefields of two receding glaciers. Microb Ecol 43: 397-407.

Srivastava DS, Cadotte MW, MacDonald AAM, Marushia RG, Mirotchnick N. (2012). Phylogenetic diversity and the functioning of ecosystems. Ecol Lett 15: 637-648.

Tilman D. (1988). Plant Strategies and the Dynamics and Structure of Plant Communities. Princeton University Press: Princeton, NJ, USA.

Turner MG, Baker WL, Peterson CJ, Peet RK. (1998). Factors influencing succession: lessons from large, infrequent natural disturbances. Ecosystems 1: 511-523.

Valiela I, Cole ML. (2002). Comparative evidence that salt marshes and mangroves may protect seagrass meadows from land-derived nitrogen loads. Ecosystems 5: 92-102.

Van der Maarel E. (2004). Vegetation Ecology. Blackwell: Malden, MA, USA.

Van Raij B, Andrade JC, Cantarella H, Quaggio JA. (2001). Análise Química Para Avaliação Da Fertilidade De Solos Tropicais. Instituto Agronômico de Campinas: Campinas, Brazil.

Van Wijnen HJ, Bakker JP, de Vries Y. (1997). Twenty years of salt marsh succession on a Dutch coastal barrier island. J Coast Conservat 3: 9-18.

Walker LR, del Moral R. (2003). Primary Succession and Ecosystem Rehabilitation. Cambridge University Press: Cambridge, UK.

Walker LR, Wardle DA, Bardgett RD, Clarkson BD. (2010). The use of chronosequences in studies of ecological succession and soil development. J Ecol 98: 725-736.

Wang J, Yang D, Zhang Y, Shen J, van der Gast C, Hahn MW et al. (2011). Do patterns of bacterial diversity along salinity gradients differ from those observed for macroorganisms? PLoS One 6: e27597.

Wang Q, Garrity GM, Tiedje JM, Cole JR. (2007). Naive Bayesian classifier for rapid assignment of rRNA sequences into the new bacterial taxonomy. Appl Environ Microbiol 73: 5261-5267.

Whittaker RH. (1972). Evolution and measurement of species diversity. Taxon 21: 213-251.

Wu X, Zhang W, Liu G, Yang X, Hu P, Chen T et al. (2012). Bacterial diversity in the foreland of the Tianshan No. 1 glacier, China. Environ Res Lett 7: 014038.

Zhang NL, Xia JY, Yu XJ, Ma KP, Wan SQ. (2011). Soil microbial community changes and their linkages with ecosystem carbon exchange under asymmetrically diurnal warming. Soil Biol Biochem 43: 2053-2059.

Supplementary Information accompanies this paper on The ISME Journal website (http://www.nature.com/ismej) 